\title{
American Society of Hematology 2020 Podcast Collection: MPN
}

\author{
Massimo Breccia
}

Received: February 3, 2021 / Accepted: February 10, 2021 / Published online: March 13, 2021

(C) The Author(s) 2021

\section{POSCAST TRANSCRIPT}

David Gray (DG): Managing Editor of Advances in Therapy

Massimo Breccia (MB): Policlinico Umberto I-Department of Translational and Precision Medicine, Sapienza University of Rome

DG: Hello, and welcome to the Adis Rapid+ podcast series. We're bringing you a selection of podcasts covering the American Society of Hematology 2020 Conference, discussing the highlights of the data released at the conference. Today's podcast will be focusing on myeloproliferative neoplasms and the data presented at the ASH conference. Speaking to us today is Dr. Massimo Breccia, Department of Translational and Precision Medicine at the Sapienza University of Rome.

Massimo, welcome to today's podcast, and thank you so much for speaking with us. You're going to talk us through some of your top highlights of the MPN [myeloproliferative neoplasm] data from ASH 2020. A lot of important

Supplementary Information The online version contains supplementary material available at https:// doi.org/10.1007/s12325-021-01665-2.

M. Breccia $(\square)$

Policlinico Umberto I-Department of Translational and Precision Medicine, Sapienza University of

Rome, Rome, Italy

e-mail: breccia@bce.uniroma1.it data was released, so please, get us started, and tell us what your first highlight was.

MB: Thank you very much, David, for your kind invitation. So we can subdivide the presentation according to the disease; in particular, the first three for myelofibrosis. And the first one is the final analysis of the EXPAND trial [1]. As you know, the current starting dose of ruxolitinib for patients with myelofibrosis but with low platelet count is $5 \mathrm{mg}$ BID.

But evidence from the previous study that was called 258 showed that a titrated dose of $10 \mathrm{mg}$ BID could be safe and effective. So the EXPAND trial tested this dose of $10 \mathrm{mg}$ BID in 69 patients that were subdivided in two different cohorts. So one, the first one, with blood counts from 75 to 100,000 , and the second one, indeed, from 50 to 75,000 . So at first, $50 \%$ and $83 \%$ of patients discontinued the study drug, respectively. In the first cohort, the main reason was progression of disease; indeed, in the second cohort, the appearance of adverse events.

So in terms of results, $40 \%$ and $38 \%$ of patients achieved a spleen reduction higher than $35 \%$ at 24 weeks, respectively. And 31\% and $40 \%$ indeed improved their symptoms, measured by the total symptom score at 24 weeks, respectively.

The pharmacokinetic analysis showed that it is similar to that of patients treated with ruxolitinib that had higher platelet count. So the results strongly suggest that the dose of $10 \mathrm{mg}$ 
BID could be used in patients with low platelet count at baseline without an increased rate of adverse events and because it seems to be effective in terms of achievement of spleen reduction and symptoms reduction.

Another important message was sent to the last ASH meeting for another new drug that was called CPI-0610, was presented only the new trial that was called MANIFEST-2, a global phase 3 randomized double blind that will test CPI plus ruxolitinib versus placebo and ruxolitinib in JAK inhibitor-naive MF [myelofibrosis] patients [2], but was based on the previous results of the MANIFEST trial that, indeed, was largely presented at the last ASH meeting. So this drug is a best-in-class new drug that was tested both in resistant refractory or naive patients.

The drug is a BET inhibitor, means that it's able to stop the bromodomain lysine residues on histone proteins, where started the transcription for several important proteins, such as BCL-XL or NF-kB, needed for survival. And in vitro, CPI, together with ruxolitinib, demonstrated strong antiproliferative and antifibrotic properties.

So the MANIFEST trial was subdivided in three different arms, arm 1, in which the drug was tested as a monotherapy in advanced phases of disease. In 16 transfusion-dependent patients, $21 \%$ converted to transfusion independence. Indeed, 27 patients without transfusion independence were enrolled. And in this cohort, $24 \%$ of them achieved splenic volume reduction higher than $35 \%$ after 24 weeks of treatment; $47 \%$ of them improved also symptoms present at baseline.

In the arm 2, the drug was added to ruxolitinib in suboptimal responders. And in 44 transfusion-dependent patients, $34 \%$ become transfusion-independent. And 21\% achieved also the splenic volume reduction endpoint, with $46 \%$ that were able to modify their symptoms present at baseline. Twenty-six nontransfusion-dependent patients, indeed, were also enrolled. And 29\% achieved the primary endpoint of the splenic volume reduction. So overall, the other important information is that $41 \%$ of patients had at least one-grade improvement in bone marrow fibrosis.
The most important side effects recorded were thrombocytopenia, diarrhoea in half of the patients, and respiratory infections in 35\% of patients. The last arm is the arm 3 , in which the drug was associated to ruxolitinib in 78 naive patients, the majority of them with high IPSS risk. The primary endpoint is, again, the achievement of a splenic volume reduction higher than $35 \%$, this time reached by $67 \%$ of patients at 24 weeks. And $57 \%$ had an improvement in symptoms. And 33\% achieved at least one-grade improvement in bone marrow fibrosis.

And again, even in the naive patients, the most common side effects recorded were thrombocytopenia and diarrhoea. So the results showed that CPI probably is one of the most promising drugs to be used in combination with ruxolitinib because it's able not only to overcome the resistance to JAK2 inhibitors but also, as compared to JAK2 inhibitors, to modify the pathogenesis of the disease.

And another important combination was presented with navitoclax together with ruxolitinib. Navitoclax is a potent inhibitor of the BCL-2 family. Again, in vitro showed that it's able, together with ruxolitinib, to overcome the resistance to JAK2 inhibitors, but also to potentiate the antifibrotic effect. It was previously tested in a phase 2 trial that was presented at the last ASH meeting as an update in 34 patients, $58 \%$ of them with important high-risk mutations at baseline.

The splenic volume reduction endpoint was achieved by $27 \%$ of patients. And $29 \%$ indeed achieved a reduction in bone marrow fibrosis of at least one grade; $30 \%$ of them indeed improved in the symptoms present at baseline. And the responses were reported regardless of baseline mutational status. And another important information not previously reported is that the drug seems to improve also the cytokine production level, in particular in patients that reached splenic response and improvement of symptoms.

So based on these results, another trial is ongoing that was presented only at the last ASH meeting, called TRANSFORM-2, a phase 3 [study] that randomized patients refractory or relapsed after only one line of therapy to 
navitoclax plus ruxolitinib versus best available therapy [3]. The primary endpoint, as always, is the splenic volume reduction higher than 35\%. And in the best available therapy, ruxolitinib and also fedratinib are allowed.

DG: Brilliant. Thank you, Massimo. And I know that you also spent some time looking at the polycythaemia vera [PV] data. So what were some of the key highlights in that area?

MB: Yeah, so it was presented the final analysis of the RESPONSE-2 trial, a trial that enrolled resistant or intolerant patients to hydroxyurea that were randomized to ruxolitinib $10 \mathrm{mg}$ BID versus best available therapy, with a possible crossover after 28 weeks of treatment [4]. This final analysis showed about the durability of haematocrit control and safety. Ninety-seven patients had a long-term followup.

So the haematocrit control was achieved by $21.6 \%$. And in patients treated with ruxolitinib, that started early, as compared also to patients that crossed over, and so with that delayed treatment. It's the phlebotomies rate that was lower in patients that start ruxolitinib early, as compared to patients that crossed over.

So $12 \%$ of patients achieved also a durable complete haematologic response. And other important data showed that the JAK2 allelic burden was constantly reduced, that $45 \%$ of patients improved in their symptoms, and that the ruxolitinib reduced also the rate of thromboembolic events, as compared to the best available therapy.

In terms of safety, indeed, well known, the anaemia related to the drug, arthralgia, increased weight, possible herpes zoster reactivation, and also increased evidence of nonmelanoma skin cancer. So the final analysis suggested that ruxolitinib could be used as a second-line therapy in patients with not controlled PV without splenomegaly. But we have to perform a better selection of candidates to this drug due to the possible infective episodes, viral reactivation, and also the possible occurrence of skin cancers.

The other communication is about a new drug, called idasanutlin, that is an MDM2 antagonist leads to increased p53 activity reduction in JAK2-mutated patients. The first results of a phase 2 trial were presented in patients resistant and/or intolerant, again, to hydroxyurea, phlebotomy-dependent [5]. So 27 patients enrolled, but at week 22, only 16 [were] available. And of them, nine obtained a haematocrit control, and eight, a complete hematologic response, with an overall response rate of $69 \%$, regardless of the splenomegaly at baseline.

Twenty-three patients were also evaluable for molecular responses. And it seems that the drug reduced the JAK2 allelic burden areas after three cycles. And these responses were sustained after 32 weeks of treatment. So the study also, interestingly, demonstrated that $68 \%$ of patients had germline variants detected in DNA repair genes. And this may contribute to genomic instability.

Another possible drug for resistant PV patients. And [for] the selection of candidates, we should consider the gastrointestinal safety profile of the drug.

DG: Well, thank you, Massimo, for this brilliant whistle-stop tour of some of the important highlights of the MPN data at ASH 2020. Listeners, please do join us again for more in this same series.

You can listen to more podcasts by subscribing to Adis Rapid+ podcast with your preferred podcast provider, or by visiting the website. A full list of declarations, including funding and author disclosure statements, can also be found on the journal website.

\section{DIGITAL FEATURES}

This article is published with digital features, including a podcast video and audio file, to facilitate understanding of the article. To view digital features for this article go to https://doi. org/10.6084/m9.figshare.13704655.

\section{ACKNOWLEDGEMENTS}

Funding. This podcast has been developed independently through an unrestricted educational grant by Novartis. The Rapid Service Fee 
was funded by an unrestricted educational grant by Novartis.

Authorship. The named author meets the International Committee of Medical Journal Editors (ICMJE) criteria for authorship for this article, takes responsibility for the integrity of the work as a whole, and has given approval for this version to be published.

Disclosures. Massimo Breccia is on the Editorial Board of Advances in Therapy but has nothing further to disclose.

Compliance with Ethics Guidelines. This article does not contain any studies with human participants or animals performed by the author.

Peer Review. Please note, contrary to the journal's standard single-blind peer review process, as a podcast this article underwent review by a member of the journal's Editorial Board.

Open Access. This article is licensed under a Creative Commons Attribution-NonCommercial 4.0 International License, which permits any non-commercial use, sharing, adaptation, distribution and reproduction in any medium or format, as long as you give appropriate credit to the original author(s) and the source, provide a link to the Creative Commons licence, and indicate if changes were made. The images or other third party material in this article are included in the article's Creative Commons licence, unless indicated otherwise in a credit line to the material. If material is not included in the article's Creative Commons licence and your intended use is not permitted by statutory regulation or exceeds the permitted use, you will need to obtain permission directly from the copyright holder. To view a copy of this licence, visit http://creativecommons.org/licenses/by$\mathrm{nc} / 4.0 /$.

\section{REFERENCES}

1. Guglielmelli P, Kiladjian J-J, Vannucchi A, et al. The final analysis of expand: a phase $1 \mathrm{~b}$, open-label, dosefinding study of ruxolitinib (RUX) in patients (pts) with myelofibrosis (MF) and low platelet (PLT) count $(50 \times 109 /$ L to $<100 \times 109 /$ L $)$ at baseline. ASH 2020 conference. 2020. https://ash.confex.com/ash/2020/ webprogram/Paper137742.html.

2. Mascarenhas J, Harrison G, Luptakova K, et al. MANIFEST-2, a global, phase 3, randomized, doubleblind, active-control study of CPI-0610 and ruxolitinib vs. placebo and ruxolitinib in JAK-inhibitornaive myelofibrosis patients. ASH 2020 conference. 2020. https://ash.confex.com/ash/2020/webprogram/ Paper140901.html.

3. Dilley K, Harb D, Jalaluddin M, Hutti JE, Potluri J. A phase 3, open-label, randomized study evaluating the efficacy and safety of navitoclax plus ruxolitinib versus best available therapy in patients with relapsed/refractory myelofibrosis (TRANSFORM-2). ASH 2020 conference. 2020. https://ash.confex.com/ ash/2020/webprogram/Paper139247.html.

4. Passamonti F, Palandri F, Saydam G, et al. Long-term effect of ruxolitinib (RUX) in inadequately controlled polycythemia vera (PV) without splenomegaly: 5-year results from the phase 3 response- 2 study. ASH 2020 conference. 2020. https://ash.confex.com/ash/2020/ webprogram/Paper139281.html.

5. Mascarenhas J, Harrison G, Luptakova K, et al. Molecular response patterns in hydroxyurea (HU)-resistant or intolerant polycythemia vera (PV) during treatment with idasanutlin: results of an open-label, single-arm phase 2 study. ASH 2020 conference. 2020 . https://ash.confex.com/ash/2020/ webprogram/Paper140901.html. 